\title{
Five Orders-of-Magnitude Enhancement of Two-Photon Absorption for Dyes on Silver Nanoparticle Fractal Clusters
}

\author{
Wim Wenseleers, ${ }^{\dagger}$ Francesco Stellacci, Timo Meyer-Friedrichsen, Timo Mangel, \\ Christina A. Bauer, Stephanie J. K. Pond, Seth R. Marder,* and Joseph W. Perry*
}

Department of Chemistry, The University of Arizona, Tucson, Arizona 85721

Received: December 31, 2001 ; In Final Form: March 7, 2002

\begin{abstract}
Strong enhancement of the two-photon absorption of organic molecules near silver nanoparticle fractal clusters has been observed and has been exploited to yield composite materials with very strong two-photon absorption and two-photon-excited fluorescence properties. Measurements on cluster films coated with chromophoric polymer or with thiol-bound chromophores give spatially-averaged enhancements of 1000 and 20000 , respectively. Two-photon fluorescence microscopy studies show that the enhancements are spatially inhomogeneous, with peak-enhancement factors of $\geq 10000$ (polymer/cluster) and $\geq 160000$ (thiol chromophore/cluster), and excitation frequency dependent. These results are in accord with theoretical predictions of local-field effects due to strong localization of collective plasmon modes in fractal metal clusters, and demonstrate an approach to ultrasensitive two-photon processes.
\end{abstract}

\section{Introduction}

Composite systems based on metal nanoparticles and surfaces offer possibilities for enhancement of optical responses, such as surface-enhanced Raman scattering (SERS) and second harmonic generation, due in part to large local field effects. ${ }^{1-3}$ It is thought that giant local fields, leading to strongly enhanced nonlinear optical responses, can be generated in the vicinity of fractal clusters of metal nanoparticles. ${ }^{4}$ A nonlinear optical process of current interest is two-photon absorption (TPA), wherein two quanta of light are absorbed simultaneously, which provides a means for three-dimensionally resolved excitation of materials. Applications of TPA being actively pursued include three-dimensional fluorescence microscopy, ${ }^{5}$ optical data storage ${ }^{6}$ microfabrication, ${ }^{7}$ and optical limiting. ${ }^{8}$ TPA is typically a weak process that requires high intensity for excitation, even with chromophores specifically designed to have a large TPA cross-section.

Local field enhancement of two-photon-excited fluorescence (TPF) has been obtained for molecules on smooth metal surfaces ${ }^{9}$ and on evaporated silver island films, ${ }^{10}$ resulting in a 90 and 150-fold increase, respectively. Enhancement of TPF has also been realized by illuminating a gold tip, ${ }^{11}$ and this was used for ultrahigh resolution $(30 \mathrm{~nm})$ near-field fluorescence imaging. Photodecomposition of pyridine and other aromatic molecules on roughened $\operatorname{Ag}(110)$ surfaces has also been attributed to an enhanced two-photon absorption process. ${ }^{12}$ Much larger enhancements of nonlinear optical effects and TPA, in particular, are expected to occur near fractal clusters of metal nanoparticles. $^{4}$

Because an applied electromagnetic field can excite collective oscillations of free electrons (plasmons) of metal nanostructures, large local fields can be generated. For example, calculations ${ }^{11}$

\footnotetext{
* To whom correspondence should be addressed: E-mail: jwperry@ u.arizona.edu (JWP), smarder@u.arizona.edu (SRM).

Current address: Physics Department, University of Antwerp, 2610 Wilrijk-Antwerpen, Belgium.
}

of the local electric field distribution at a gold tip give an intensity enhancement factor of 1000 . Theoretical studies by Shalaev et al. ${ }^{4,13,14}$ have predicted an even stronger enhancement of optical processes near semi-continuous metal films and metal nanoparticle clusters with a random fractal geometry. ${ }^{15}$ Whereas a periodic lattice $(1,2$, or $3 \mathrm{D})$ of metal particles can support traveling plasmon waves, aggregates of metal particles possessing a fractal geometry (noninteger dimension) lack translational symmetry and therefore exhibit strongly localized plasmon modes. Importantly, interaction of the particles in the fractal cluster leads to a redistribution of the plasmon amplitude from a large number of particles into a much larger amplitude localized on a few particles, producing giant local fields in subwavelength sized "hotspots". The coupled plasmon resonances of fractal clusters extend to long wavelengths relative to the single particle plasmon resonance, and span a broad region of the spectrum (visible to IR), allowing for strong resonance effects over a wide wavelength range. Due to the inhomogeneous nature of the coupled resonances, the locations of the hotspots are predicted to be excitation wavelength dependent. Direct evidence for localization of optical fields near metal nanoparticle fractal clusters has been obtained using near-field optical microscopy. ${ }^{16}$ Because optical responses scale with a power of the local field, molecules residing in hotspots can exhibit strongly enhanced responses. This picture offers one way to explain the electromagnetic contribution to SERS. ${ }^{2,13,17}$

Nonlinear optical responses of molecules near fractal metal clusters are expected to be enhanced by many orders of magnitude, ${ }^{18}$ as they are proportional to a high order function of the local field. However, the use of metal fractal composites for the enhancement of nonlinear optical effects has been limited. Observations of reduction in lasing thresholds for dyes in colloidal silver suspensions ${ }^{19,20}$ and enhanced degenerate four wave mixing $(\mathrm{DFWM})^{21}$ in clustered metal nanoparticles have been reported.

There is potential for strong enhancement of multiphoton absorption effects because simultaneous absorption of $n$ photons 


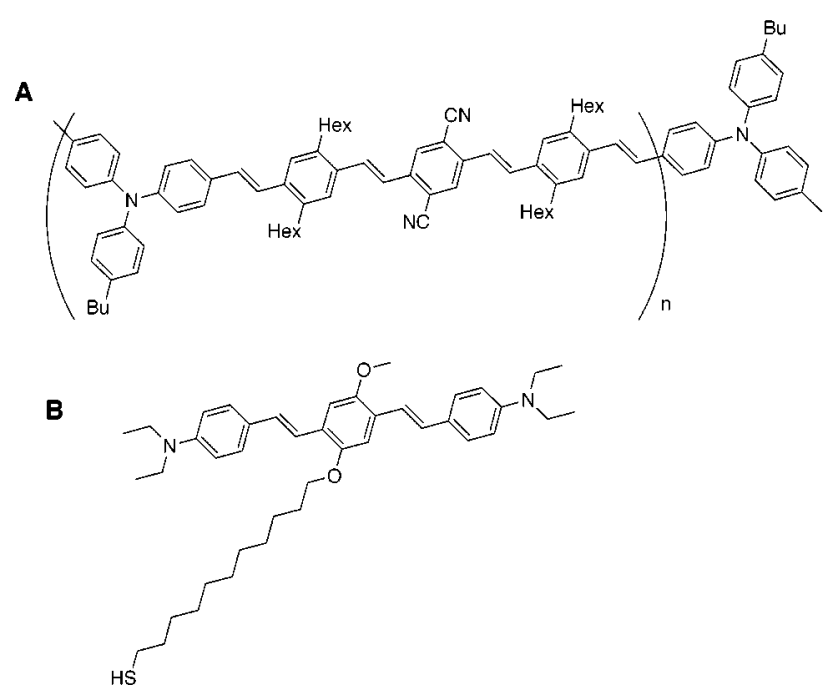

Figure 1. Structures of the chromophoric polymer (A) and thiolfunctionalized chromophore (B).

scales as $I^{n}$, where $I$ is the light intensity. Because the concentration of intensity into hotspots creates large peaks of local intensity, the net multiphoton absorption (proportional to the average value of $I^{n}$ over a given volume) can be very large compared with that for a uniform intensity distribution. Furthermore, applications of multiphoton absorption effects are not significantly hampered by slight background absorption and scattering effects involved in fractal cluster systems, as compared to nonlinear refractive index processes such as DFWM.

Here we report an investigation of the two-photon-excited fluorescence of both polymer-coated and dye-anchored fractal clusters of silver nanoparticles, and study the magnitude of the enhancement as well as its spatial variation and excitation frequency dependence.

\section{Results and Discussion}

Our experiments focused on TPA by organic chromophores at silver nanoparticle cluster surfaces. Essentially, no enhancements of TPA were observed for rhodamine $6 \mathrm{G}$ dye solutions $\left(10^{-7} \mathrm{~mol} / \mathrm{L}\right.$ as in ref 19$)$ containing colloidal silver fractal clusters, or for dye-doped ( $10 \%$ by wt) poly(methyl methacrylate) (PMMA) coated silver fractal films. We recognized that it is necessary to have a high concentration of chromophores near the surface of the fractals to effectively populate the hotspots, while minimizing the number of chromophores far from the silver that would generate a background fluorescence signal. As a first approach to achieve this, a thin film of a polymer comprised entirely of chromophoric units was coated onto a silver cluster film. Silver nanoparticle fractal films were prepared by sedimentation of clusters onto a glass substrate as described in the literature, and were characterized by various techniques (see the Experimental Section). We estimated that these films have a fractal dimension of 1.45-1.65 from optical and scanning electron microscopy (imaged perpendicular to film), using the area-perimeter method. ${ }^{22}$

The chromophoric polymer (A), whose structure is shown in Figure 1, contains donor-acceptor-donor units ${ }^{23,24}$ in the main chain that exhibit a large TPA cross section and high fluorescence quantum efficiency. It was synthesized via a Heck coupling of a divinyltriarylamine, $\mathbf{3}$, and a dicyano-substituted, diiodobis(stryryl)benzenze, 6, as shown in Scheme 1. Measurements of the TPA cross section ${ }^{25}(\delta)$ for this polymer in toluene give $\delta=1020 \times 10^{-50} \mathrm{~cm}^{4} \mathrm{~s} /$ photon per repeat unit at the peak wavelength of $890 \mathrm{~nm}$. The fluorescence quantum yield $(\eta)$ of polymer $\mathrm{A}$ is 0.83 , as measured relative to 9,10 -bis(phenylethynyl)anthracene ${ }^{26}$. The large $\eta \delta$ product of the polymer allows for sensitive detection of TPA by monitoring the TPF signal. The TPF excitation spectrum (Figure 2) of the polymer shows strong TPA over a broad wavelength region spanning from $<710$ to $>920 \mathrm{~nm}$. Amorphous polymer films of 10 to $200 \mathrm{~nm}$ thickness were cast onto the nanoparticle cluster film by solvent evaporation from dilute dichloromethane solutions.

We investigated the TPF signals from polymer coated cluster films, neat polymer films, and uncoated cluster films (the latter two serving as control samples) using $\sim 100$ fs mode-locked Ti:sapphire laser pulses with a wavelength of $\sim 800 \mathrm{~nm}$. Intensity-dependent and spectroscopic measurements provide strong evidence that the observed emission from the composite was due to TPA and was dominated by the emission from the polymer. The fluorescence signals from the composites and the control samples were observed to depend quadratically on incident laser intensity (see Figure 3) and no fluorescence was detected when a continuous-wave laser beam (with the same average intensity but peak intensity lower by $\sim 10^{5}$ ) was used, confirming an instantaneous two-photon process for all samples. The TPF emission spectrum of the composite film is different from that of the cluster film ${ }^{27}$ but very similar to that of the neat polymer, as shown in Figure 2, indicating that the emission of the composite originates from the organic chromophores.

Much stronger TPF signals were observed for the composite films than for the control films. An enhancement factor for the TPF signal can be defined as $\left(S_{\text {comp }}-S_{\mathrm{c}}\right) / S_{\mathrm{p}}$, where $S_{\text {comp }}, S_{\mathrm{c}}$, and $S_{\mathrm{p}}$ are the signals for the composite, the cluster film and the neat polymer, respectively. We obtained a large spatially averaged enhancement factor for a series of composite films, with values ranging from 50 to 250 (as measured with an unfocused beam with a cross-sectional area of $\sim 10 \mathrm{~mm}^{2}$ ) for composite films with an $\sim 100 \mathrm{~nm}$ thick polymer coating. The exact value was found to depend on the surface coverage of the silver clusters, as expected. To study the dependence on polymer film thickness a series of substrates with the same silver coverage was produced by simultaneous deposition in the same sedimentation receptacle. For polymer films with thicknesses of $10 \mathrm{~nm}$, the spatially averaged enhancement was 1000 . For thicker films, the enhancement factor (always determined relative to a neat polymer film of the same thickness) varied inversely with thickness, e.g., an enhancement factor of 90 was observed for a $100 \mathrm{~nm}$ thick film. This falloff for thicknesses $\geq 10 \mathrm{~nm}$ can be explained as follows: for all the composite films the TPF signal is dominated by the TPF from the first $<10 \mathrm{~nm}$ layer and the additional polymer at greater distance from the silver clusters does not contribute significantly to the total signal, whereas the signal for the neat polymer films grows linearly with thickness. The apparent enhancement factor therefore drops off inversely with polymer thickness. This observation is consistent with the expectation based on theory that the local field enhancement occurs only very close to the metal clusters. ${ }^{28}$

To test whether the observed phenomenon is spatially inhomogeneous, as predicted by theory, ${ }^{14}$ and if so, to estimate the magnitude of the peak enhancement factor, we imaged the TPF from the composite films by using laser-scanning fluorescence microscopy. As shown in Figure 4A, most of the TPF indeed originates from small spots, whose size is limited by the instrumental resolution of $250 \mathrm{~nm}$ (fwhm). ${ }^{29}$ Comparison of TPF images with transmission optical microscopy images 


\section{SCHEME 1}
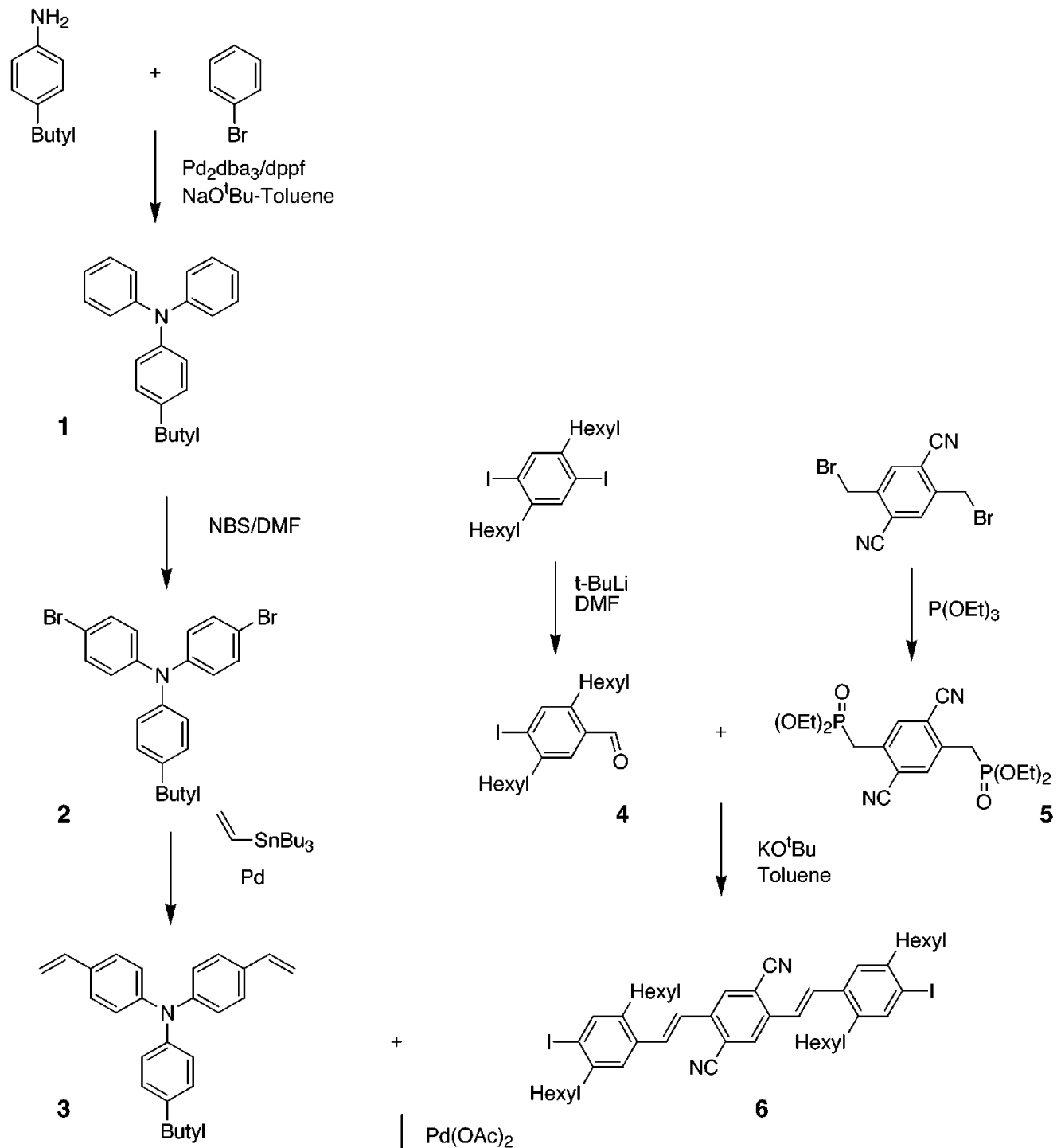

$+$

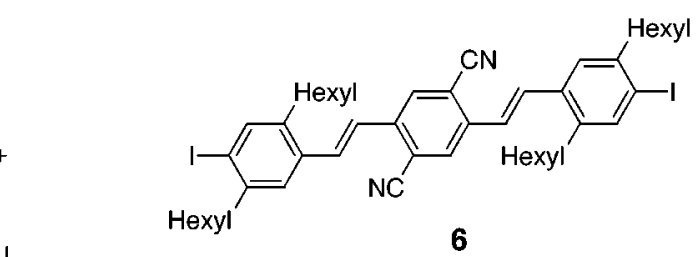

$\mathrm{Pd}(\mathrm{OAc})_{2}$ $\mathrm{P}(\mathrm{o} \text {-tolyl })_{3}$ $\mathrm{Et}_{3} \mathrm{~N} / \mathrm{DMF}$

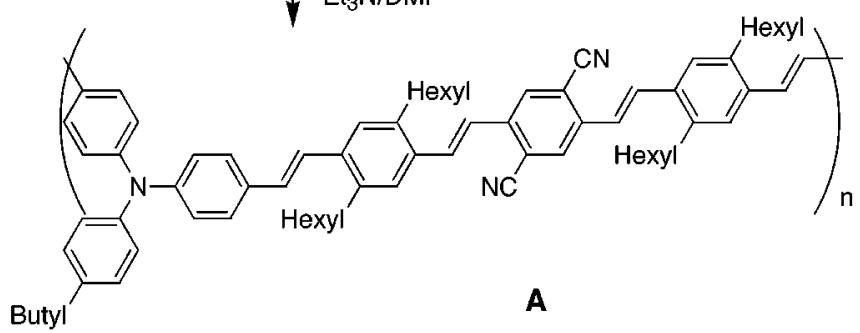

of the same film shows a strong correlation between the positions of fractal clusters and of the enhanced TPF (Figure 4 $\mathrm{B}, \mathrm{D})$. The TPF enhancement are observed only from distinct spots within a cluster, not from the whole cluster, as will be discussed below. The peak TPF signal in these spots is at least an order-of-magnitude larger than the spatially averaged signal. A quantity of interest is the peak enhancement factor of the TPF intensity generated by a molecule residing in a hotspot relative to that of a molecule in the absence of the metal clusters. Combining the spatially resolved imaging results with the thickness dependent measurements on the composite films, we deduce that the peak enhancement factor of the TPF is $\geq 10000$ for the polymer coated nanoparticle cluster composites.

Another prediction of theory is that the positions of the hotspots are dependent on the excitation wavelength. ${ }^{14} \mathrm{We}$ performed two-photon laser-scanning fluorescence microscopy to obtain images of the same region of a composite film using different laser wavelengths. Indeed, we observed a distinct and reproducible pattern of hotspot positions for each excitation wavelength used (Figure 4B). The spatially resolved and clearly visible colors in the false color overlay image arise from resonances being excited with different wavelengths, and confirm the frequency dependence of the plasmon localization. With the ability to perform excitation frequency-dependent spatial imaging, TPF can be a useful tool for studying localization of plasmons, which is of interest in the context of Anderson localization. ${ }^{30}$

Enhancement factors obtained using collimated excitation beams at different angles of incidence, as well as under tight focusing conditions (numerical aperture $=1.4$, cone-half-angle 


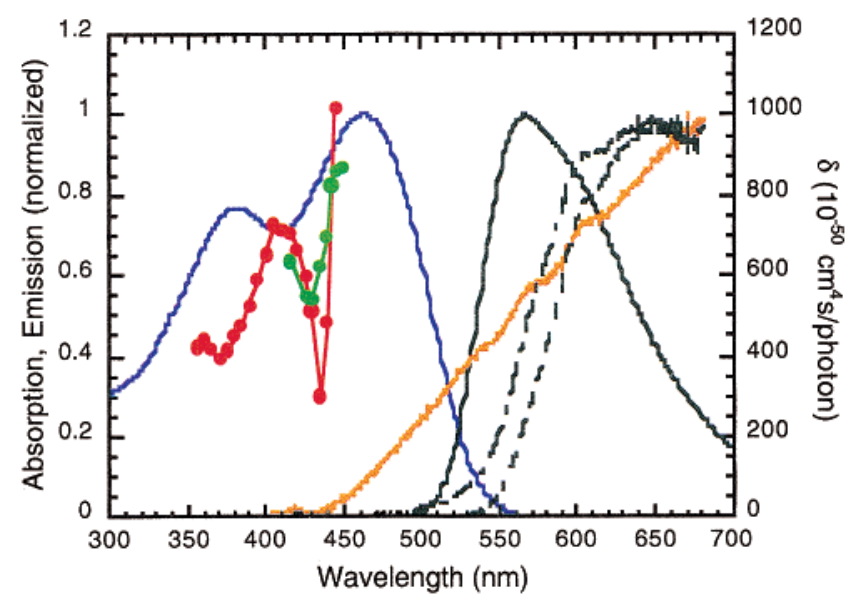

Figure 2. One-photon and two-photon spectra of polymer (A), composite, and metal cluster films. One-photon absorption spectrum of polymer in toluene solution (blue). Two-photon fluorescence excitation spectrum of polymer in toluene solution (femtosecond data in red, nanosecond data in green), calibrated against Coumarin 307 in methanol (ref 25) and plotted against half the excitation wavelength. One-photon-excited fluorescence spectrum of polymer in toluene solution (solid black line). Two-photon-excited emission spectra $\left(\lambda_{\mathrm{exc}}\right.$ $=800 \mathrm{~nm}$ ) of the neat polymer film (dashed black line), the polymer/ cluster composite film (dash-dotted black line), and the neat metal cluster film (orange).

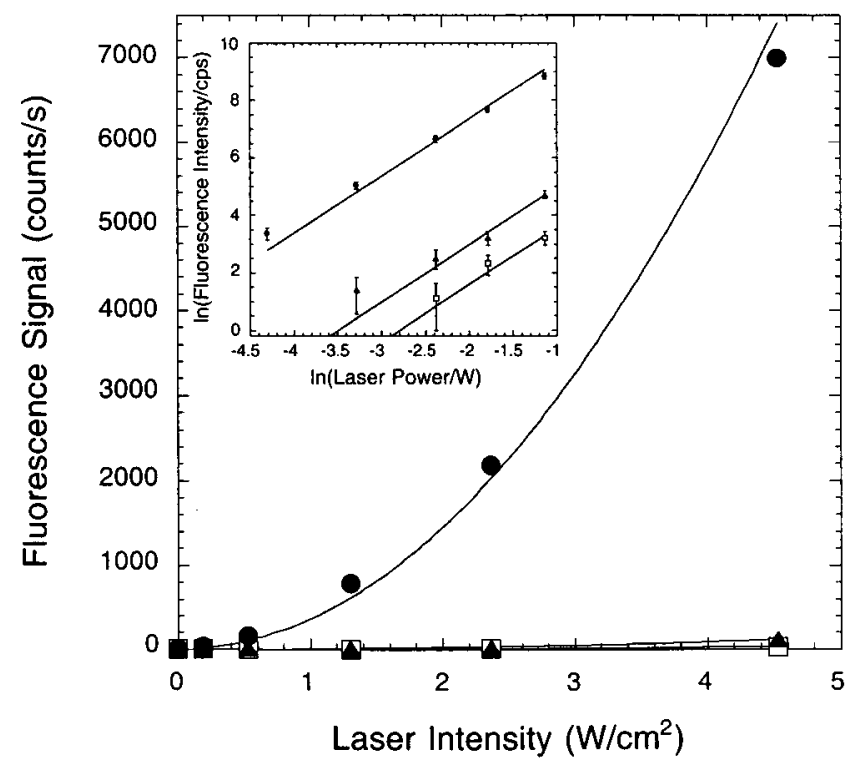

Figure 3. Laser power dependence of the two-photon-excited fluorescence intensity from a polymer/silver-cluster composite film (circles), neat polymer film (squares), and silver cluster film (triangles). Experiments were conducted using a $3 \mathrm{~mm}$ diameter collimated laser beam. Inset shows the same data on a double logarithmic plot. The solid lines are quadratic fits to the data.

of $68^{\circ}$ ), were similar, showing that the enhancement is relatively insensitive to the angle of incidence. This is rather different behavior from that observed for two-photon-excited fluorescence enhancement due to coupling to surface-plasmon modes of smooth metal films, ${ }^{9}$ which occurs only at a particular angle of incidence, as dictated by wavevector matching conditions. We rule out a significant contribution of multiple scattering to the observed enhancement in the composite films because the total optical density of the silver cluster films, including absorptive and scattering losses, was only in the range of 0.05 to $0.3(90 \%$ to $50 \%$ transmission).
To investigate whether the large enhancements depend on the coupling of particles in the fractal clusters, we compared the TPF of dyes attached to isolated nanoparticles and fractal clusters. In the sedimented silver films, the formation of fractal clusters is intrinsic to the deposition process. However, by using silver nanoparticles coated with alkylthiol ligands, aggregation of nanoparticles is suppressed, and isolated nanoparticles can be studied in solution. We synthesized nanoparticles in which a fraction of the alkylthiol coating was exchanged with a thiolfunctionalized two-photon dye (B; see Figure 1). The thiol containing two-photon chromophore, $\mathbf{B}$, was synthesized in six steps from 4-methoxyphenol as shown in Scheme 2. We compared the one- and two-photon-excited fluorescence from such nanoparticles with those of the free dye, both in toluene solution and in PMMA films.

The fluorescence signal of the dye molecules bound to the nanoparticles was reduced by a factor of 4.5 compared to that of the free dye, as observed using one- or two-photon excitation (at 450 and $730 \mathrm{~nm}$, respectively) of toluene solutions with the same total dye concentration (see also the Experimental Section). It should be noted that there was no significant emission from analogous particles without dye. One possible interpretation of these results is that neither the one- nor the two-photon absorption cross sections are significantly changed when the dye is bound to the particles, but the emission quantum yield of the dye is reduced from $75 \%$ to $17 \%$. Alternatively, it could be that both the one- and the two-photon absorptions are enhanced, and the fluorescence quantum yield is reduced by a larger factor. However, as one would expect the fluorescence quantum yield to be the same in both cases, this would imply that the one- and the two-photon absorption have the same average enhancement factor, which is very unlikely given the different powers of the local fields involved in the two absorption processes.

For the PMMA films, the ratio of two-photon-excited fluorescence to the one-photon excited fluorescence was found to be the same for the films containing dye-coated nanoparticles and for PMMA films containing free dye. Thus, within experimental error, no enhancement of the two-photon absorption is observed for these isolated particles, whereas large enhancements are observed for the coupled particles in the fractal clusters, confirming the importance of the particle interactions in the enhancement mechanism.

As an intermediate case to the fractal clusters and the isolated nanoparticles, we investigated neat films of the dye-attached ligand-coated nanoparticles. It is well established ${ }^{31}$ that, upon casting by solvent evaporation, alkylthiol-coated nanoparticles form partially ordered arrays, with a particle spacing of about one ligand length, due to the interdigitation of alkyl chains. Reference films comprising dye coated nanoparticles dissolved in a PMMA matrix were used for comparison to the neat nanoparticle films. However, it was difficult to prepare reference films with the same number of dye molecules within the interaction volume of the excitation beam compared to the neat nanoparticle film. Therefore, for this experiment, we used a normalization scheme based on the one-photon excited fluorescence intensity. In this way, an estimate of the enhancement of the TPA itself is obtained (see the Experimental Section). We observed that dye-attached nanoparticle films (thickness $\approx$ $20 \mathrm{~nm}$ ) showed a measurable but relatively small enhancement of TPA by a factor of 5, relative to the same nanoparticles dispersed in a PMMA film (see also the Experimental Section). In contrast, the same dye bound to a Ag fractal cluster film showed an enhancement in TPA (spatially averaged) by a factor 
A

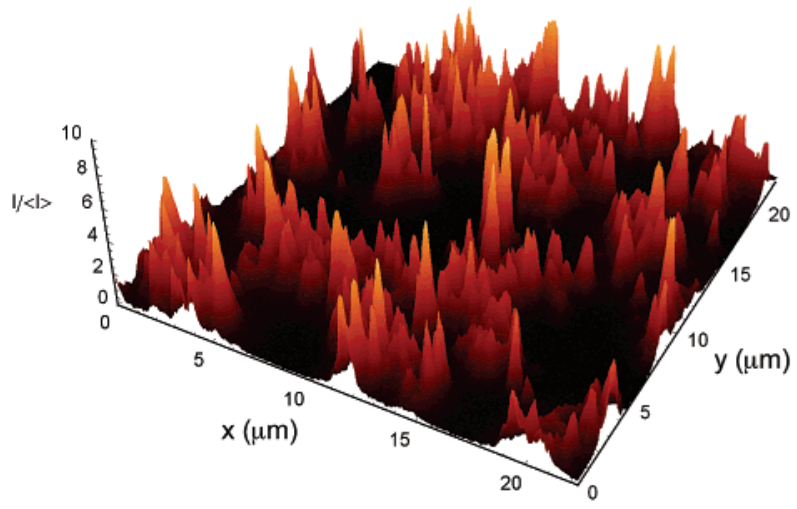

B

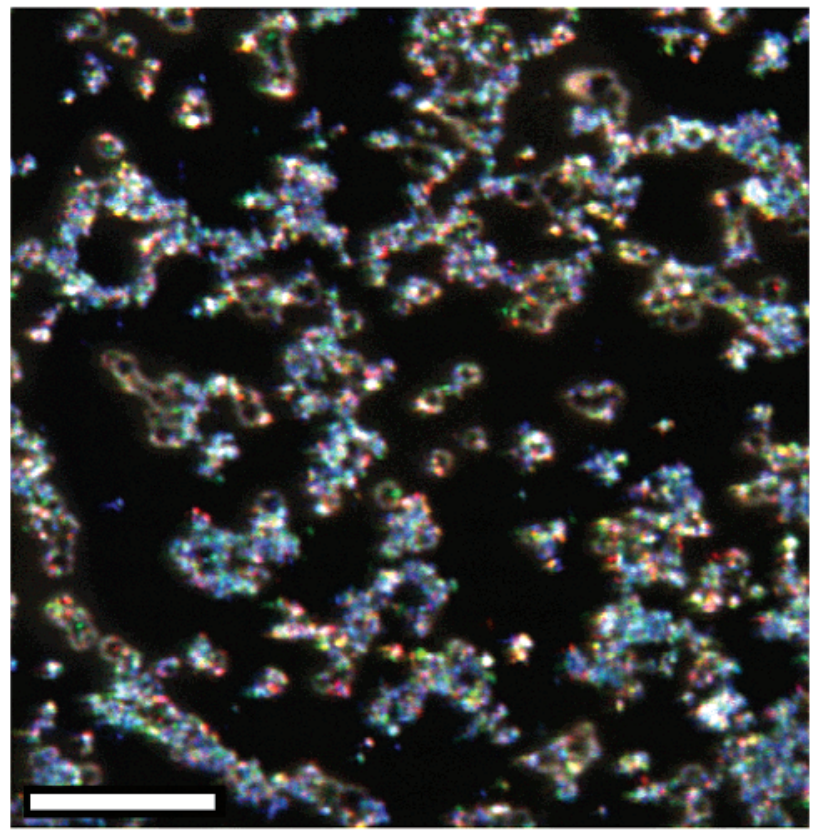

C
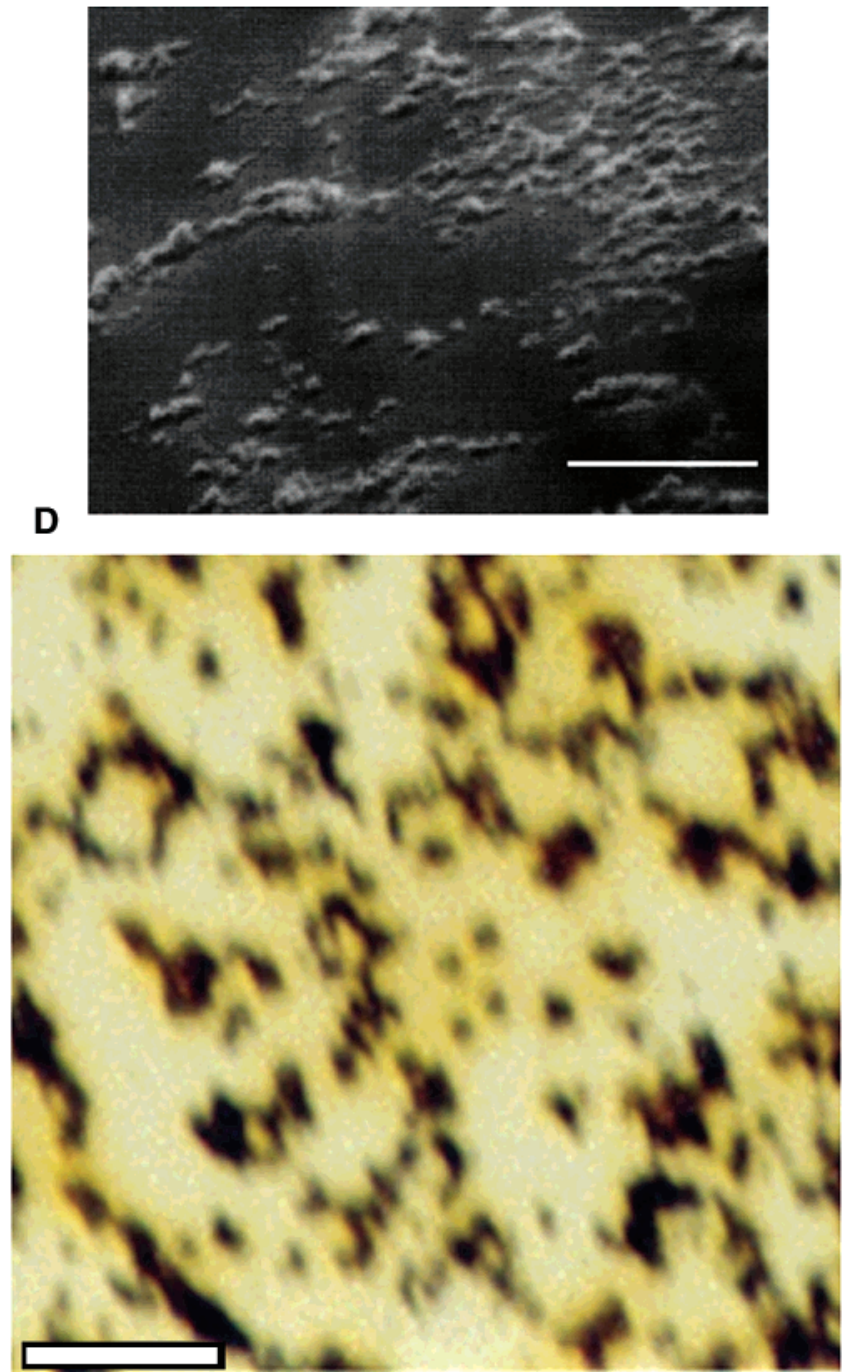

Figure 4. Two-photon laser-scanning fluorescence, scanning electron, and transmission optical microscopy images of polymer/silver-cluster composites. (A) Plot of TPF intensity excited at $890 \mathrm{~nm}$ versus x,y position in the film, showing the presence of the hotspots. (B) False-color overlay of TPF images obtained at three different excitation wavelengths: $720 \mathrm{~nm}$ (shown in blue), $820 \mathrm{~nm}$ (green), and $890 \mathrm{~nm}$ (red), showing the frequency dependence of the hotspot positions (scale bar: $10 \mu \mathrm{m}$ ). (C) Scanning electron microscopy image of the Ag fractal clusters deposited on indium tin oxide (scale bar: $5 \mu \mathrm{m}$ ). (D) Transmission optical microscopy image of the same area of the Ag cluster/polymer composite of Figure 4B (scale bar: $10 \mu \mathrm{m}$ ).

of $\sim 20000$. These results further emphasize the importance of the particle spacing and spatial distribution in the enhancement mechanism. Using TPF microscopy, we again observed an 8 -fold increase of the peak to the average TPF signals and thus deduced a peak TPA enhancement factor of $>160000$ for the chromophores attached to the fractal clusters. These TPA enhancements are also much larger than those observed on evaporated silver island films. ${ }^{10}$ This is consistent with the fact that the nanoparticle aggregates formed in colloidal solution through the mechanism of cluster-cluster aggregation (CCA) have a fractal geometry ${ }^{32}$ that closely approximates that of the simulated CCA aggregates for which extremely large enhancements have been calculated. ${ }^{33}$ In contrast, the evaporated films have a far more regular "droplet-like" structure. ${ }^{34}$

The large enhancement of two-photon absorption by metal nanoparticle fractal clusters has potential for application in ultrasensitive detection of molecular binding, ${ }^{35}$ imaging, and localized activation of photochemical processes. An important consequence of the enhancement of the effective TPA crosssection by five orders-of-magnitude is that it allows for the use of a several hundred-fold lower laser intensity to produce a given fluorescence signal, which can be of significance in biological applications. We believe that metal nanoparticle fractal clusters are interesting systems with potential to increase the impact of two-photon processes in photonics, materials processing, chemical sensing, and biological applications.

\section{Conclusions}

In conclusion, our studies show that organic chromophores near the surface of clusters of silver nanoparticles with a random fractal geometry exhibit large enhancements in two-photon absorption and two-photon-excited fluorescence, relative to isolated chromophores. In polymer coated films, chromophores within $\$ 10 \mathrm{~nm}$ of the surface show an enhancement in TPF of 1000 and we estimate the peak values in the hotspots of the clusters to be $>10000$. For dyes that are chemically bound within a distance of $\lesssim 15 \AA$, the spatially averaged enhancement of TPA is $\sim 20000$, whereas the peak values are $\gtrsim 160000$. By comparing results on isolated ligand-coated nanoparticles with attached dyes, partially ordered films of such particles, 


\section{SCHEME 2}
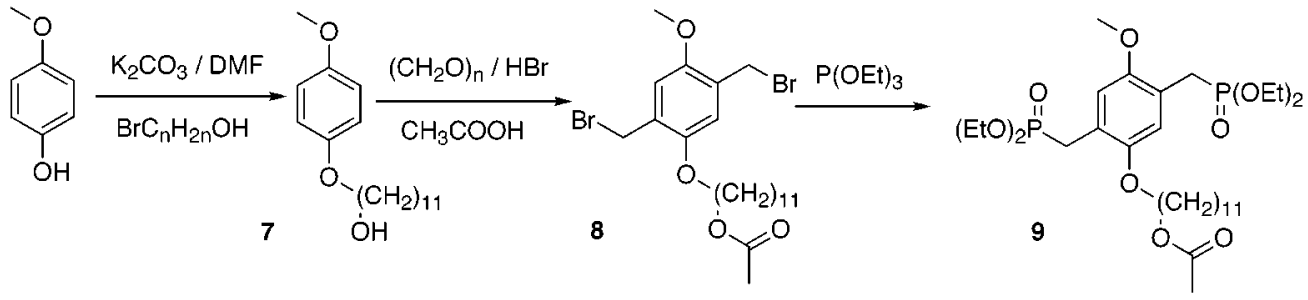

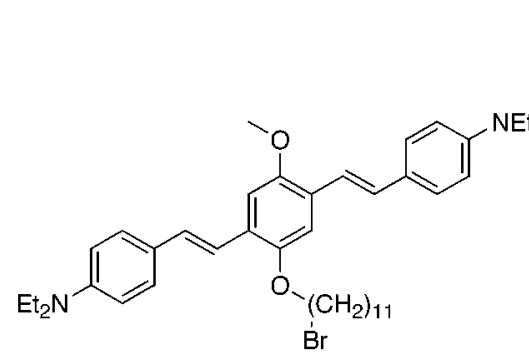

11

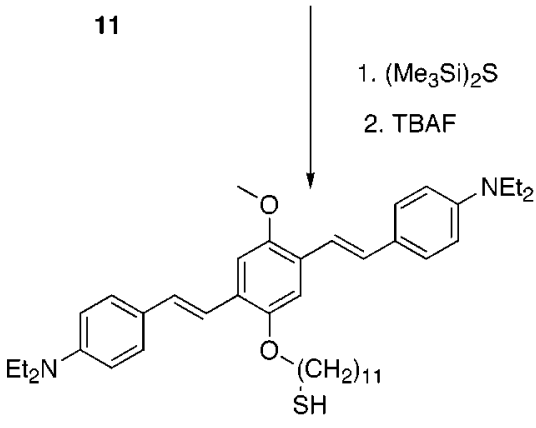<smiles>CCNc1ccc(/C=C/c2cc(OCOC(C)=O)c(/C=C/c3ccc(N(CC)CC)cc3)cc2OC)cc1</smiles>

B

and fractal clusters with attached dyes, we conclude that interactions of silver nanoparticles in fractal cluster arrangements are critical to the magnitude of the enhancement, consistent with the theoretical results of Shalaev et al. Furthermore, our studies show that the enhancements are localized on the clusters, with the locations of strong enhancement depending on excitation wavelength, also in qualitative agreement with theory. Further studies aimed at the optimization of these effects, including the effect of distance and orientation of the chromophores relative to the silver surface, and the use of other metals are in progress.

\section{Experimental Section}

All solvents and reagents were purchased from Aldrich as reagent grade and used as received. Spectrophotometric grade solvents were used for optical measurements, cleaning, and filmcasting. Optical absorption spectra were measured using either a diode array spectrometer (HP 8453) or a Varian Cary 5E UVvis-NIR spectrometer. Fluorescence spectra for fluorescence quantum yield determinations were recorded using a Spex Fluorolog 2. Fluorescence quantum yields were determined relative to 9,10-bis-(phenylethynyl)-anthracene. ${ }^{26}$ Laser excited emission spectra were recorded using a spectrograph (SpectraPro 150, Acton Research Corp.) with liquid nitrogen cooled CCD detection (Princeton Instruments LN/CCD-1100-PB). Scanning electron microscopy was performed on a Hitachi S-2460N. Gas chromatography detected by mass spectrometry (GC-MS) was performed using an HP 6890 gas chromatograph equipped with a mass selective detector HP 5973. Elemental analyses were performed by Atlantic Microlab Inc., Norcross, GA or by Desert Analytics Laboratory, Tucson, AZ. NMR spectra were recorded using a General Electric QE-300 spectrometer $(300 \mathrm{MHz}$ for ${ }^{1} \mathrm{H}$ and $75 \mathrm{MHz}$ for ${ }^{13} \mathrm{C}$ ), or using a Varian 500 spectrometer $\left(500 \mathrm{MHz}\right.$ for ${ }^{1} \mathrm{H}$ and $125 \mathrm{MHz}$ for ${ }^{13} \mathrm{C}$ ). If microanalyses are not reported, the purity of the compounds were judged to be $>90 \%$ by ${ }^{1} \mathrm{H}$ NMR and ${ }^{13} \mathrm{C}$ NMR. All the reported yields are isolated yields unless otherwise indicated. High-resolution mass spectroscopy was performed by the Department of Chemistry, University of California at Irvine

Silver Nanoparticle Cluster Film Preparation. Silver nanoparticles were prepared by reduction of silver nitrate with sodium citrate in aqueous solution. ${ }^{36}$ Cluster formation was induced by adding $15 \mathrm{~mL}$ of $0.026 \mathrm{M}$ aqueous fumaric acid to $500 \mathrm{~mL}$ of silver colloid solution. ${ }^{18}$ The amount of fumaric acid was chosen so that cluster formation was clearly observable by monitoring the optical absorption spectrum of the colloid (see the Supporting Information). Precipitated clusters were deposited on substrates over one to three days in a receptacle filled to a height of $2.5 \mathrm{~cm}$ with the colloid. The substrates were then carefully taken out of the solution, dried, and then immersed in pure water again to remove any residual reagents. After the films had been dried once, the silver was attached strongly enough to the glass for further processing, such as solvent casting or rinsing with solvents. The films were characterized by optical absorption spectroscopy, optical microscopy, TPF microscopy, scanning and transmission electron microscopy, and atomic force microscopy. The particle mean diameter was found to be 10 $\mathrm{nm}$ from TEM images. The optical spectra of the silver fractal films were very similar to those of the aqueous colloids, showing the typical cluster band ${ }^{2}$ with an optical density in the range of 0.05 to 0.3 . Upon sedimentation, as well as upon drying of the 
films after sedimentation, the cluster band shifts to longer wavelengths - consistent with further aggregation.

Coating Cluster Films with Thiolated Dye, B. The thiolsubstituted dye, B, was coated onto silver cluster films by solvent evaporation from dichloromethane solution, followed by repeated immersion in neat dichloromethane to remove unbound dye. The complete removal of the unbound dye was established by checking that after the last two immersions the solvent showed no fluorescence.

Synthesis of TPA Polymer, A. The following starting materials were prepared according to literature methods: 1,4diiodo-2,5-dihexylbenzene ${ }^{37}$ and 2,5-dicyano-1,4-bis(bromomethyl)benzene. ${ }^{38}$

4-Butyl- $\boldsymbol{N}, \boldsymbol{N}$-diphenyl-aniline (1). To a solution of tris(dibenzylideneacetone)dipalladium $\left(\mathrm{Pd}_{2} \mathrm{dba}_{3}\right)$ (1.099 $\mathrm{g}, 1.2$ $\mathrm{mmol}$ ) and bis(diphenylphosphino)ferrocene (dppf) (0.998 g, $1.8 \mathrm{mmol})$ in toluene $(180 \mathrm{~mL})$ under nitrogen atmosphere was added bromobenzene $(28.264 \mathrm{~g}, 180 \mathrm{mmol})$ and the resultant solution was stirred for $10 \mathrm{~min}$ at ambient temperature. To this solution were then added sodium tert-butoxide (14.417 g, 150 mmol) and 4-butylaniline (8.954 g, $60 \mathrm{mmol})$. The resultant solution was stirred at $90{ }^{\circ} \mathrm{C}$ for $60 \mathrm{~h}$ under nitrogen atmosphere. After $36 \mathrm{~h}$ an additional amount of catalyst $\left(\mathrm{Pd}_{2} \mathrm{dba}_{3}(366 \mathrm{mg}\right.$, $0.4 \mathrm{mmol}$ ) and dppf (333 $\mathrm{mg}, 0.6 \mathrm{mmol})$ ) and base (sodium tert-butoxide (4.806 g, $50 \mathrm{mmol})$ ) was added to the solution. The reaction mixture was cooled to room temperature and separated between ether and water layers. The combined organic layer was concentrated using rotary evaporation, and purified using flash column chromatography $\left(\mathrm{SiO}_{2} /\right.$ hexane) to obtain $16.84 \mathrm{~g}(93 \%)$ of the product as a viscous, slightly yellow oil. ${ }^{1} \mathrm{H}$ NMR $\left(300 \mathrm{MHz}, \mathrm{CDCl}_{3}\right) \delta 7.27(\mathrm{~d}, J=7.4 \mathrm{~Hz}, 2 \mathrm{H}), 7.25$ $(\mathrm{d}, J=7.4 \mathrm{~Hz}, 2 \mathrm{H}), 7.15-6.96(\mathrm{~m}, 10 \mathrm{H}), 2.62(\mathrm{t}, J=7.7 \mathrm{~Hz}$, $2 \mathrm{H}), 1.70-1.58(\mathrm{~m}, 2 \mathrm{H}), 1.48-1.37(\mathrm{~m}, 2 \mathrm{H}), 0.99(\mathrm{t}, J=7.3$ $\mathrm{Hz}, 3 \mathrm{H}) .{ }^{13} \mathrm{C} \mathrm{NMR}\left(75 \mathrm{MHz}, \mathrm{CDCl}_{3}\right) \delta 148.0,145.3,137.7$, 129.1, 129.0, 124.7, 123.6, 122.2, 35.0, 33.7, 22.4, 14.0.

4-Butyl- $\boldsymbol{N}, \boldsymbol{N}$-bis(4-bromophenyl)-aniline (2). To a solution of 4-butyl- $N, N$-bis(phenyl)aniline (1) $(6.024 \mathrm{~g}, 20 \mathrm{mmol})$ in DMF (60 mL) was added N-bromosuccinimide (NBS) (7.112 $\mathrm{g}, 40 \mathrm{mmol})$. The resultant solution was stirred for $20 \mathrm{~h}$ at ambient temperature. The reaction mixture was separated between ether and water layers and the organic layer was concentrated using rotary evaporation to yield $8.45 \mathrm{~g}(92 \%)$ of the product as a slight brown, very viscous oil. Further purification was achieved by using column chromatography $\left(\mathrm{SiO}_{2} / 20 \%\right.$ dichloromethane in hexane). ${ }^{1} \mathrm{H}$ NMR $(300 \mathrm{MHz}$, $\left.\mathrm{CDCl}_{3}\right) \delta 7.30(\mathrm{dd}, J=8.9 \mathrm{~Hz}, J=2.5 \mathrm{~Hz}, 4 \mathrm{H}), 7.07(\mathrm{~d}, J=$ $8.5 \mathrm{~Hz}, 2 \mathrm{H}), 6.96(\mathrm{~d}, J=8.5 \mathrm{~Hz}, 2 \mathrm{H}), 6.90(\mathrm{dd}, J=8.5 \mathrm{~Hz}, J$ $=2.5 \mathrm{~Hz}, 4 \mathrm{H}), 2.56(\mathrm{t}, J=7.8 \mathrm{~Hz}, 2 \mathrm{H}), 1.63-1.51(\mathrm{~m}, 2 \mathrm{H})$, $1.42-1.30(\mathrm{~m}, 2 \mathrm{H}), 0.93(\mathrm{t}, J=7.3 \mathrm{~Hz}) .{ }^{13} \mathrm{C} \mathrm{NMR}(75 \mathrm{MHz}$, $\left.\mathrm{CDCl}_{3}\right) \delta 146.7,138.8,132.2,129.4,125.0,124.9,114.9,35.0$, 33.6, 22.4, 14.0. HR-MS: calcd. for $\mathrm{C}_{22} \mathrm{H}_{21} \mathrm{NBr}_{2} 457.0041$ found 457.0039 .

4-Butyl- $\boldsymbol{N}, \boldsymbol{N}$-bis(4-ethenylphenyl)-aniline (3). To a solution of 4-butyl- $N, N$-bis(4-bromophenyl)aniline (2) (1.225 g, 2.660 $\mathrm{mmol}), \mathrm{Pd}\left(\mathrm{PPh}_{3}\right)_{4}(61.69 \mathrm{mg}, 0.053 \mathrm{mmol})$ and a few crystals of 2,6-di-tert-butyl-4-methylphenol in toluene $(7 \mathrm{~mL})$ was added tributyl(vinyl)tin $(2.093 \mathrm{~g}, 6.6 \mathrm{mmol})$. The resulting solution was heated to reflux for $20 \mathrm{~h}$. After cooling the reaction mixture was diluted with ether $(100 \mathrm{~mL})$ and washed with $2 \mathrm{~N} \mathrm{HCl}$ and water. The organic layer was dried with $\mathrm{MgSO}_{4}$ and the solvent was removed using rotary evaporation. The residue was purified using column chromatography $\left(\mathrm{SiO}_{2} / 20 \%\right.$ dichloromethane in hexane) to yield $453 \mathrm{mg}$ (48\%) of a slightly yellow impure oil, that was used in the next step without further purification. ${ }^{1} \mathrm{H}$
NMR (300 MHz, $\left.\mathrm{CDCl}_{3}\right) \delta 7.26(\mathrm{~d}, J=7.6 \mathrm{~Hz}, 4 \mathrm{H}), 7.06(\mathrm{~d}$, $J=8.5 \mathrm{~Hz}, 2 \mathrm{H}), 7.04-6.96(\mathrm{~m}, 6 \mathrm{H}), 6.64(\mathrm{dd}, J=17.6 \mathrm{~Hz}, J$ $=10.9 \mathrm{~Hz}, 2 \mathrm{H}), 5.62(\mathrm{dd}, J=17.6 \mathrm{~Hz}, J=0.6 \mathrm{~Hz}, 2 \mathrm{H}), 5.14$ $(\mathrm{d}, J=10.9 \mathrm{~Hz}, 2 \mathrm{H}), 2.56(\mathrm{t}, J=7.6 \mathrm{~Hz}, 2 \mathrm{H}), 1.63-1.51(\mathrm{~m}$, $2 \mathrm{H}), 1.44-1.30(\mathrm{~m}, 2 \mathrm{H}), 0.93(\mathrm{t}, J=7.3 \mathrm{~Hz}, 3 \mathrm{H}) .{ }^{13} \mathrm{C} \mathrm{NMR}$ $\left(75 \mathrm{MHz}, \mathrm{C}_{3} \mathrm{D}_{6} \mathrm{O}\right) \delta 148.4,145.9,139.3,137.3,132.9,130.3$, 128.1, 126.0, 124.2, 112.5, 35.7, 34.6, 23.1, 14.3. GC-MS: 353 $\left(\mathrm{M}^{+}\right)$. El. Anal. Calcd. for $\mathrm{C}_{26} \mathrm{H}_{27} \mathrm{~N}$ : C, 88.34; H, 7.70, N, 3.86. Found: C, 86.08; H, 7.62; N, 3.81 .

4-Iodo-2,5-dihexylbenzaldehyde (4). To a solution of 1,4diiodo-2,5-dihexylbenzene (4.98 g, $10 \mathrm{mmol})$ in THF $(80 \mathrm{~mL})$ at $-78^{\circ} \mathrm{C}$ under nitrogen was added $t$-BuLi $(13.8 \mathrm{~mL}, 1.45 \mathrm{M}$ solution in pentane, $20 \mathrm{mmol}$ ) and the resultant solution was stirred at this temperature for $30 \mathrm{~min}$. Then, dimethylformamide $(2.3 \mathrm{~mL}, 30 \mathrm{mmol})$ was added to the solution and the mixture was stirred at $-78^{\circ} \mathrm{C}$ for $1 \mathrm{~h}$ and at room temperature for $3 \mathrm{~h}$. The solvent was evaporated and the residue was separated between ether and water layers. The organic layer was dried with $\mathrm{MgSO}_{4}$ and the solvent removed using rotary evaporation to yield $3.43 \mathrm{~g}$ of the crude product. Crystallization from ethanol gave a small amount of relatively pure $\mathbf{4}$, whereas the compound seems to decompose during chromatography on silica gel. ${ }^{1} \mathrm{H}$ NMR $\left(300 \mathrm{MHz}, \mathrm{CDCl}_{3}\right) \delta 10.19(\mathrm{~s}, 1 \mathrm{H}), 7.73(\mathrm{~s}, 1 \mathrm{H}) 7.57(\mathrm{~s}$, $1 \mathrm{H}), 2.88(\mathrm{t}, J=7.8 \mathrm{~Hz}, 2 \mathrm{H}), 2.70(\mathrm{t}, J=7.9 \mathrm{~Hz}, 2 \mathrm{H}), 1.56$ $(\mathrm{m}, 4 \mathrm{H}), 1.30(\mathrm{~m}, 12 \mathrm{H}), 0.87(\mathrm{~m}, 6 \mathrm{H})$.

Tetraethyl-(2,5-dicyano- $\alpha, \alpha^{\prime}-p$-xylylenediphosphonate) (5). $314 \mathrm{mg}$ (1 mmol) of 2,5-dicyano-1,4-bis(bromoethyl)benzene and $500 \mathrm{mg}$ ( $3 \mathrm{mmol})$ of triethyl phosphite were heated to 160 ${ }^{\circ} \mathrm{C}$ for $18 \mathrm{~h}$. Then the excess of triethyl phosphite was removed using rotary evaporation and the residue was crystallized from hexane/ethyl acetate (1:1). $280 \mathrm{mg}$ of beige crystals were

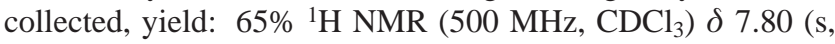
$2 \mathrm{H}), 4.13\left(\mathrm{~m}, 8 \mathrm{H}, \mathrm{OCH}_{2}\right), 3.38\left(\mathrm{~d}, J=21 \mathrm{~Hz}, 4 \mathrm{H}, \mathrm{CH}_{2}\right)$, $1.30\left(\mathrm{t}, J=7.25 \mathrm{~Hz}, 12 \mathrm{H}, \mathrm{CH}_{3}\right) .{ }^{13} \mathrm{C} \mathrm{NMR}\left(125 \mathrm{MHz}, \mathrm{CDCl}_{3}\right)$ $\delta 16.24,31.83(\mathrm{~d}, J=139 \mathrm{~Hz}), 62.71,115.87,117.45,134.77$, 135.64. El. Anal. Calcd. for $\mathrm{C}_{18} \mathrm{H}_{26} \mathrm{~N}_{2} \mathrm{O}_{6} \mathrm{P}_{2}: \mathrm{C}, 50.47, \mathrm{H}, 6.12$, N, 6.54, P, 14.46, O, 22.41. Found: C, 50.76, H, 6.34, N, 6.65, $\mathrm{P}, 14.22, \mathrm{O}, 22.03$.

$\boldsymbol{E}, \boldsymbol{E}$-1,4-Bis(4-iodo-2,5-di- $\boldsymbol{n}$-hexylstyryl)-2,5-dicyano-benzene (6). To a stirred solution of the bisphoshonate (5) $(535.2$ $\mathrm{mg}, 1.25 \mathrm{mmol}$ ) and 4-iodo-2,5-dihexyl-benzaldehyde (4) (1.02 $\mathrm{g}, 2.54 \mathrm{mmol})$ in THF (10 mL) under nitrogen was slowly added a suspension of KO- $t \mathrm{Bu}(291.2 \mathrm{mg}, 2.6 \mathrm{mmol})$ in THF $(5 \mathrm{~mL})$. After $2.5 \mathrm{~h}$, the reaction was quenched with water and the solution was separated between water and ether layers. The organic layer was dried with $\mathrm{MgSO}_{4}$ and the solvent was removed using rotary evaporation. The residue was purified using column chromatography $\left(\mathrm{SiO}_{2}\right.$ /hexane/methylenchloride (2:1)) to yield $580 \mathrm{mg}$ (50\% of the pure all-trans product 6 ). ${ }^{1} \mathrm{H}$ NMR (300 MHz, $\left.\mathrm{CD}_{2} \mathrm{Cl}_{2}\right) \delta 8.06(\mathrm{~s}, 2 \mathrm{H}), 7.70(\mathrm{~s}, 2 \mathrm{H})$, $7.55(\mathrm{~d}, J=16.1 \mathrm{~Hz}, 2 \mathrm{H}), 7.49(\mathrm{~s}, 2 \mathrm{H}), 7.29(\mathrm{~d}, J=16.1 \mathrm{~Hz}$, $2 \mathrm{H}), 2.70(\mathrm{~m}, 8 \mathrm{H}), 1.64-1.52(\mathrm{~m}, 16 \mathrm{H}), 1.45-1.26(\mathrm{~m}, 16$ $\mathrm{H}), 0.93-0.86(\mathrm{~m}, 12 \mathrm{H}) .{ }^{13} \mathrm{C} \mathrm{NMR}\left(75 \mathrm{MHz}, \mathrm{CD}_{2} \mathrm{Cl}_{2}\right) \delta 144.2$, $141.7,141.2$, 139.8, 135.0, 132.8, 131.1, 127.0, 124.1, 117.2, 115.7, 102.1, 41.0, 33.0, 32.3, 31.9, 31.0, 29.7, 29.6, 23.3, 23.2, 14.4. El. Anal. Calcd. for $\mathrm{C}_{48} \mathrm{H}_{62} \mathrm{I}_{2} \mathrm{~N}_{2}$ : C, 62.61; H, 6.79; I, 27.56; N, 3.04. Found: C, 62.49; H, 6.98; I, 27.30; N, 2.84.

TPA-Polymer Derived from 3 and 6 (A). 4-Butyl- $N, N$-bis(4-ethenylphenyl)-aniline (3) (176.6 mg, $0.5 \mathrm{mmol}), E, E-1,4-$ Bis(4-iodo-2,5-di-n-hexylstyryl)-2,5-dicyano-benzene (6) (460.2 $\mathrm{mg}, 0.5 \mathrm{mmol}), \mathrm{Pd}(\mathrm{OAc})_{2}(6.3 \mathrm{mg}, 0.025 \mathrm{mmol}), \mathrm{P}(\mathrm{o}-\text { tolyl })_{3}$ (39 $\mathrm{mg}, 0.25 \mathrm{mmol}$ ) were dissolved in DMF $(8 \mathrm{~mL})$, toluene $(5 \mathrm{~mL})$ and triethylamine $(0.29 \mathrm{~mL})$ under nitrogen atmosphere. Then the solution was heated at $80{ }^{\circ} \mathrm{C}$ for $20 \mathrm{~h}$. After this time 
4-butyl- $N, N$-bis(4-ethenylphenyl)-aniline (25 mg, $0.07 \mathrm{mmol}$ ) was added, because thin-layer chromatography still showed some 6, but no 3. After $44 \mathrm{~h} \mathrm{Pd}(\mathrm{OAc})_{2}$ (4.7 mg, $0.019 \mathrm{mmol}$ ), $\mathrm{P}$ (o-tolyl) $)_{3}(30 \mathrm{mg}, 0.19 \mathrm{mmol})$ and an additional amont of 4-butyl- $N, N$-bis(4-ethenylphenyl)-aniline (29 mg, $0.08 \mathrm{mmol}$ ) were added and the solution was heated for further $22 \mathrm{~h}$ at 100 ${ }^{\circ} \mathrm{C}$. Then the reaction mixture was added dropwise into methanol $(500 \mathrm{~mL})$ and the precipitate was collected by filtration. The polymer was redissolved in a small amount of dichloromethane and added dropwise into hexane $(500 \mathrm{~mL})$. After filtration the product was dried under vacuum. The yield of the orange polymer was $400 \mathrm{mg}(79 \%) .{ }^{1} \mathrm{H}$ NMR $\left(300 \mathrm{MHz}, \mathrm{CDCl}_{3}\right) \delta$ 8.03 (bs, $2 \mathrm{H}), 7.63-6.97$ (m, $24 \mathrm{H}), 2.85-2.65$ (m, $8 \mathrm{H}), 2.65-$ $2.52(\mathrm{~m}, 2 \mathrm{H}), 1.71-1.52(\mathrm{~m}, 10 \mathrm{H}), 1.50-1.26(\mathrm{~m}, 26 \mathrm{H})$, 0.95-0.82 (m, $15 \mathrm{H}){ }^{13} \mathrm{C}$ NMR $\left(75 \mathrm{MHz}, \mathrm{CD}_{2} \mathrm{Cl}_{2}\right) \delta 144.2$, $141.7,141.2,139.8,135.0,132.8,131.1,127.0,124.1,117.2$, 115.7, 102.1, 41.0, 33.0, 32.3, 31.9, 31.0, 29.7, 29.6, 23.3, 23.2, 14.4. GPC: $M_{\mathrm{n}}=12030, M_{\mathrm{w}}=31220$, determined relative to a polystyrene standard.

Synthesis of the Thiol Functionalized Chromophore. 11(4-methoxyphenoxy)undecan-1-ol (7): $\mathrm{NaH}$ (4.8 g, $200 \mathrm{mmol})$ was suspended in dry THF $(250 \mathrm{~mL})$ and 4-methoxyphenol (24.7 $\mathrm{g}, 199 \mathrm{mmol}$ ) was added portionwise. The reaction was cooled with an ice bath and after the gas evolution had ended 11-bromoundecanol (50 g, $199 \mathrm{mmol}$ ) was added. The reaction was stirred for $1 \mathrm{~h}$ at room temperature and then heated to reflux. The progress of the reaction was followed by GC-MS. After $19 \mathrm{~h}$, the reaction was completed. Water and $\mathrm{CH}_{2} \mathrm{Cl}_{2}$ were added and the organic layer was separated. The water layer was washed two times with $\mathrm{CH}_{2} \mathrm{Cl}_{2}$. The combined organic layers were dried over $\mathrm{MgSO}_{4}$, were filtered, and the solvent was evaporated. Recrystallization from $\mathrm{CH}_{2} \mathrm{Cl}_{2}$ gives $51.81 \mathrm{~g}$ white solid (88.4\%). ${ }^{1} \mathrm{H}$ NMR (500 MHz, $\left.\mathrm{CDCl}_{3}\right) \delta 6.81$ (br s, 4H), 3.88 $\left(\mathrm{t}, J=6.5 \mathrm{~Hz}, 2 \mathrm{H},-\mathrm{OCH}_{2}\right), 3.75\left(\mathrm{~s}, 3 \mathrm{H},-\mathrm{OCH}_{3}\right), 3.62(\mathrm{t}, J$ $\left.=6.5 \mathrm{~Hz}, 2 \mathrm{H}, \mathrm{HOCH}_{2^{-}}\right), 1.73(\mathrm{~m}, 2 \mathrm{H}), 1.54(\mathrm{~m}, 2 \mathrm{H}), 1.42(\mathrm{~m}$, $2 \mathrm{H}), 1.27(\mathrm{~m}, 12 \mathrm{H}) \mathrm{ppm} ;{ }^{13} \mathrm{C}$ NMR $\left(125 \mathrm{MHz}, \mathrm{CDCl}_{3}\right) \delta: 153.62$, 153.27, 115.40, 114.59, 70.98, 68.63, 63.10, 55.74, 32.81, 29.56, 29.55, 29.51, 29.43, 29.40, 26.20, 26.05, 25.73 ppm. GC-MS: (19.11 min) m/z (\%): 294 (17) M, 124 (100) $\mathrm{M}-\mathrm{C}_{11} \mathrm{H}_{22} \mathrm{O}$. El. Anal. Calcd. for $\mathrm{C}_{18} \mathrm{H}_{30} \mathrm{O}_{3}$ : C: $73.43 \mathrm{H}$ : 10.27 Found: C: 73.55, H: 10.38 .

11-[2,5-Bis(bromomethyl)-4-methoxyphenoxy]undecyl acetate (8): To a suspension of 11-(4-methoxyphenoxy)undecan1-ol (7) (51.8 g, $177 \mathrm{mmol})$ and p-formaldehyde (10.57 g, 352 mmol) in $\mathrm{CH}_{3} \mathrm{COOH}(250 \mathrm{~mL})$ was added $\mathrm{HBr}(100 \mathrm{~mL}$ of a $33 \% \mathrm{HBr}$ solution in $\left.\mathrm{CH}_{3} \mathrm{COOH}\right)$ at once. The suspension became clear and the reaction was kept at $80{ }^{\circ} \mathrm{C}$ for $30 \mathrm{~h}$, and the progress was followed by GC-MS. After pouring into water $(300 \mathrm{~mL})$, the white precipitate was filtered off, washed with water and dried using rotary evaporation. The product contained slight impurities but was used without further purification steps. Crude yield: $28.14 \mathrm{~g}(30.5 \%) .{ }^{1} \mathrm{H}$ NMR $\left(500 \mathrm{MHz}, \mathrm{CDCl}_{3}\right) \delta$ : $6.84(\mathrm{~s}, 1 \mathrm{H}), 6.83(\mathrm{~s}, 1 \mathrm{H}), 4.51\left(\mathrm{~s}, 2 \mathrm{H},-\mathrm{CH}_{2} \mathrm{Br}\right), 4.50(\mathrm{~s}, 2 \mathrm{H}$, $\left.-\mathrm{CH}_{2} \mathrm{Br}\right), 4.03\left(\mathrm{t}, J=6.5 \mathrm{~Hz}, 2 \mathrm{H},-\mathrm{OCH}_{2}-\right), 3.96(\mathrm{t}, J=6.0$ $\left.\mathrm{Hz}, 2 \mathrm{H},-\mathrm{OCH}_{2}-\right), 3.84\left(\mathrm{~s}, 3 \mathrm{H},-\mathrm{OCH}_{3}\right), 3.38(\mathrm{t}, J=7.0 \mathrm{~Hz}$, 2H), $2.02\left(\mathrm{~s}, 3 \mathrm{H},-\mathrm{CH}_{3}\right), 1.79(\mathrm{~m}, 2 \mathrm{H}), 1.59(\mathrm{~m}, 2 \mathrm{H}), 1.40(\mathrm{~m}$, 2H), $1.27(\mathrm{~m}, 12 \mathrm{H}) \mathrm{ppm} ;{ }^{13} \mathrm{C} \mathrm{NMR}\left(125 \mathrm{MHz}, \mathrm{CDCl}_{3}\right) \delta$ : 171.48, 151.29, 150.99, 127.74, 127.51, 114.91, 113.90, 69.17, 64.87, 56.42, 29.74, 29.69, 29.63, 29.51, 29.46, 29.43, 28.93, 28.88, 28.80, 26.27, 26.12, 21.26 ppm. El. anal.calcd. for $\mathrm{C}_{22} \mathrm{H}_{34}-$ $\mathrm{Br}_{2} \mathrm{O}_{4}: \mathrm{C}: 50.59 \mathrm{H}: 6.56$ found $\mathrm{C}: 50.57, \mathrm{H}: 6.82$.

11-\{2,5-bis[(diethoxyphosphoryl)methyl]-4-methoxyphenoxy $\}$ undecyl acetate (9): 11-[2,5-bis(bromomethyl)-4-methoxyphenoxy] undecyl acetate (8) (3.40 g, $6.5 \mathrm{mmol})$ and triethyl phosphite $(2.5 \mathrm{~mL}, 14.5 \mathrm{mmol})$ were heated to $160^{\circ} \mathrm{C}$ for $8 \mathrm{~h}$. After removing the volatiles, the product was chromatographed on silica 60 (ethyl acetate) to give $3.34 \mathrm{~g}(81 \%)$ of a white solid. ${ }^{1} \mathrm{H}$ NMR $\left(500 \mathrm{MHz}, \mathrm{CDCl}_{3}\right) \delta: 6.89(\mathrm{~s}, 1 \mathrm{H}), 6.87(\mathrm{~s}$, $1 \mathrm{H}), 4.04-3.96(\mathrm{~m}, 10 \mathrm{H}), 3.89\left(\mathrm{t}, J=6.5 \mathrm{~Hz}, 2 \mathrm{H},-\mathrm{OCH}_{2}-\right)$, $3.77\left(\mathrm{~s}, 3 \mathrm{H},-\mathrm{OCH}_{3}\right), 3.21\left(\mathrm{~d}, J_{\mathrm{P}-\mathrm{H}}=21.0 \mathrm{~Hz}, 2 \mathrm{H}\right), 3.18(\mathrm{~d}$, $\left.J_{\mathrm{P}-\mathrm{H}}=21.0 \mathrm{~Hz}, 2 \mathrm{H}\right), 2.02\left(\mathrm{~s}, 3 \mathrm{H},-\mathrm{CH}_{3}\right), 1.73(\mathrm{~m}, 2 \mathrm{H}), 1.59$ $(\mathrm{m}, 2 \mathrm{H}), 1.41(\mathrm{~m}, 2 \mathrm{H}), 1.26(\mathrm{~m}, 12 \mathrm{H}), 1.21(\mathrm{t}, J=7.0 \mathrm{~Hz}$, $\left.12 \mathrm{H}, \mathrm{P}-\mathrm{OCH}_{2} \mathrm{CH}_{3}\right) \mathrm{ppm} ;{ }^{13} \mathrm{C} \mathrm{NMR}\left(125 \mathrm{MHz}, \mathrm{CDCl}_{3}\right) \delta$ : $171.49,151.12,150.68,119.80,119.47,115.24,114.13,69.22$, $64.87,62.14,62.09,62.04,56.33,29.80,29.74,29.69,29.47$, $28.81,27.23,27.03,26.35,26.13,25.93,21.26,16.60,16.56$ ppm.

11-(2,5-bis $\{(E)-2-[4-(d i e t h y l a m i n o) p h e n y l]$ ethenyl $\}-4-m e t h-$ oxyphenoxy)-1-undecanol (10): To 11-\{2,5-bis[(diethoxyphosphoryl)methyl]-4-methoxyphenoxy\}undecyl acetate (9) (5.57 g, $8.75 \mathrm{mmol})$, 4-(N,N-diethylamino)benzaldehyde $(3.102 \mathrm{~g}$, $17.5 \mathrm{mmol})$ in THF $(125 \mathrm{~mL})$, was added $\mathrm{KO}^{\mathrm{t} B u}(22.75 \mathrm{~mL}$ of $1 \mathrm{M}$ solution in THF) at room temperature. The reaction was stirred with $\mathrm{NaOH}$ solution ( $30 \mathrm{~mL}, 3 \mathrm{M}$ solution) for 1 day. $\mathrm{CH}_{2} \mathrm{Cl}_{2}$ was added, the organic layer separated, dried over $\mathrm{MgSO}_{4}$, filtered and evaporated. Chromatography (ethyl acetate: hexanes 1:3) and recrystallization from toluene gives 1.42 g $(25 \%)$ product. ${ }^{1} \mathrm{H}$ NMR $\left(500 \mathrm{MHz}, \mathrm{CDCl}_{3}\right) \delta: 7.40(\mathrm{~d}, J=$ $8.5 \mathrm{~Hz}, 2 \mathrm{H}), 7.39$ (d, $J=8.5 \mathrm{~Hz}, 2 \mathrm{H}), 7.25$ (d, $J=16.0 \mathrm{~Hz}$, $1 \mathrm{H}, E-\mathrm{CH}=\mathrm{CH}-$ ), 7.22 (d, $J=16.5 \mathrm{~Hz}, 1 \mathrm{H}, E-\mathrm{CH}=\mathrm{CH}-), 7.09$ (s, 1H), 7.07 (s, 1H), 7.02 (d, $J=16.5 \mathrm{~Hz}, 1 \mathrm{H}, E-\mathrm{CH}=\mathrm{CH}-$ ), $6.98(\mathrm{~d}, J=16.5 \mathrm{~Hz}, 1 \mathrm{H}, E-\mathrm{CH}=\mathrm{CH}-), 6.65(\mathrm{~d}, J=8.0 \mathrm{~Hz}$, $2 \mathrm{H}), 6.64(\mathrm{~d}, J=9.0 \mathrm{~Hz}, 2 \mathrm{H}), 4.01\left(\mathrm{t}, J=6.5 \mathrm{~Hz}, 2 \mathrm{H},-\mathrm{OCH}_{2}-\right.$ ), $3.88\left(\mathrm{~s}, 3 \mathrm{H},-\mathrm{OCH}_{3}\right), 3.60\left(\mathrm{t}, J=6.0 \mathrm{~Hz}, 2 \mathrm{H},-\mathrm{CH}_{2} \mathrm{O}-\right)$, $3.37\left(\mathrm{t}, J=6.5 \mathrm{~Hz}, 4 \mathrm{H},-\mathrm{NCH}_{2}-\right), 3.36(\mathrm{t}, J=6.5 \mathrm{~Hz}, 4 \mathrm{H}$, $\left.-\mathrm{NCH}_{2}-\right), 1.84\left(\mathrm{~m}, 2 \mathrm{H},-\mathrm{CH}_{2}-\right), 1.53(\mathrm{~m}, 4 \mathrm{H}), 1.38(\mathrm{~m}, 2 \mathrm{H})$, $1.29(\mathrm{~m}, 10 \mathrm{H}), 1.17\left(\mathrm{~m}, 12 \mathrm{H},-\mathrm{NCH}_{2} \mathrm{CH}_{3}\right) \mathrm{ppm} ;{ }^{13} \mathrm{C} \mathrm{NMR}(125$ $\left.\mathrm{MHz}, \mathrm{CDCl}_{3}\right) \delta: 151.41,150.96,150.45,147.41,128.75$ 128.59, $128.06,128.00,127.11,126.77,125.75,125.66,118.81,118.48$, $111.92,111.89,110.54,108.78,69.95,63.31,56.68,44.61$ $\left(-\mathrm{NCH}_{2}-\right), 33.03,29.84,29.79,29.76,29.66,26.49,25.94$, $12.89\left(-\mathrm{NCH}_{2} \mathrm{CH}_{3}\right)$ ppm. El. Anal. Calcd. for $\mathrm{C}_{42} \mathrm{H}_{60} \mathrm{~N}_{2} \mathrm{O}_{3}$ : C: $78.70 \mathrm{H}: 9.44 \mathrm{~N}: 4.37$ Found: C: $78.05, \mathrm{H}: 9.59 \mathrm{~N}: 4.28$.

4-[(E)-2-(2-[(11-bromoundecyl)oxy]-4- $\{(E)-2-[4-(d i e t h y l-$ amino)phenyl]ethenyl $\}-5$-methoxyphenyl)ethenyl]- $N, N$-diethylaniline (11): 11-(2,5-bis $\{(E)-2$-[4-diethylamino)phenyl]ethenyl \}-4-methoxyphenoxy)-1-undecanol (10) (252 mg, 0.393 $\mathrm{mmol})$ and $\mathrm{CBr}_{4}(163 \mathrm{mg}, 0.492 \mathrm{mmol})$ were dissolved in dry $\mathrm{CH}_{2} \mathrm{Cl}_{2}(2 \mathrm{~mL})$ and cooled with an ice bath. Triphenylphosphine (155 mg, $0.590 \mathrm{mmol}$ ) in $\mathrm{CH}_{2} \mathrm{Cl}_{2}(2 \mathrm{~mL}$ ) was added dropwise and the resulting solution was stirred for $5 \mathrm{~min}$. Water was added and the solution was made basic with $\mathrm{K}_{2} \mathrm{CO}_{3}$ solution. The organic layer was separated and washed with water twice, dried over $\mathrm{MgSO}_{4}$, filtered and evaporated. Flash chromatography (ethyl acetate:hexanes 2:7) gave a yellowish oil that was taken up in toluene from which slightly brown crystals grow upon cooling. $290 \mathrm{mg}$ of the product were collected and the slightly impure product was used without further purification.

${ }^{1} \mathrm{H}$ NMR $\left(500 \mathrm{MHz}, \mathrm{CDCl}_{3}\right) \delta: 7.40(\mathrm{~d}, J=8.0 \mathrm{~Hz}, 2 \mathrm{H})$, $7.39(\mathrm{~d}, J=8.5 \mathrm{~Hz}, 2 \mathrm{H}), 7.08(\mathrm{~s}, 1 \mathrm{H}), 7.07(\mathrm{~s}, 1 \mathrm{H}), 6.64(\mathrm{~m}$, $4 \mathrm{H}), 4.01(\mathrm{t}, J=6.5 \mathrm{~Hz}, 2 \mathrm{H}), 3.88\left(\mathrm{~s}, 3 \mathrm{H},-\mathrm{OCH}_{3}\right), 3.37(\mathrm{t}, J$ $\left.=7.0 \mathrm{~Hz}, 8 \mathrm{H},-\mathrm{NCH}_{2}-\right), 1.83(\mathrm{~m}, 4 \mathrm{H}), 1.52(\mathrm{~m}, 4 \mathrm{H}), 1.38(\mathrm{~m}$, $4 \mathrm{H}), 1.28(\mathrm{~m}, 6 \mathrm{H}), 1.16\left(\mathrm{~m}, 12 \mathrm{H},-\mathrm{NCH}_{2} \mathrm{CH}_{3}\right) \mathrm{ppm}$.

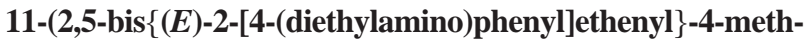
oxyphenoxy)undecan-1-thiol (B): To a solution of 4-[(E)-2(2-[(11-bromoundecyl)oxy]-4-\{(E)-2-[4-(diethylamino)phenyl]ethenyl \}-5-methoxyphenyl)ethenyl]- $N, N$-diethylaniline (11) (276 $\mathrm{mg}, 0.39 \mathrm{mmol})$ in dry $\mathrm{THF}(5 \mathrm{~mL})$ cooled to $-10{ }^{\circ} \mathrm{C}$ was 
added $\left(\left(\mathrm{CH}_{3}\right)_{3} \mathrm{Si}\right)_{2} \mathrm{~S}(100 \mu \mathrm{L}, 0.47 \mathrm{mmol})$. After stirring for 5 min. tetra- $n$-butylammonium fluoride (TBAF) $(430 \mu \mathrm{L} 1 \mathrm{M}$ solution in THF, $0.43 \mathrm{mmol}$ ) was added at once, and the reaction was allowed to warm to room temperature. After stirring for another $30 \mathrm{~min}, \mathrm{CH}_{2} \mathrm{Cl}_{2}$ was added and the solution was washed with saturated $\mathrm{NH}_{4} \mathrm{Cl}$, dried over $\mathrm{MgSO}_{4}$, filtered and evaporated. Flash chromatography (ethyl acetate:hexanes 1:5) gave $160 \mathrm{mg}(62 \%)$ product. ${ }^{1} \mathrm{H}$ NMR $\left(500 \mathrm{MHz}, \mathrm{CDCl}_{3}\right) \delta: 7.40$ $(\mathrm{d}, J=9.0 \mathrm{~Hz}, 2 \mathrm{H}), 7.39(\mathrm{~d}, J=8.5 \mathrm{~Hz}, 2 \mathrm{H}), 7.25(\mathrm{~d}, J=$ $16.0 \mathrm{~Hz}, 1 \mathrm{H}, E-\mathrm{CH}=\mathrm{CH}-), 7.22(\mathrm{~d}, J=16.0 \mathrm{~Hz}, 1 \mathrm{H}, E-\mathrm{CH}=$ CH-), 7.09 (s, 1H), 7.07 (s, 1H), $7.03(\mathrm{~d}, J=16.5 \mathrm{~Hz}, 1 \mathrm{H}$, $E-\mathrm{CH}=\mathrm{CH}-), 6.98(\mathrm{~d}, J=16.5 \mathrm{~Hz}, 1 \mathrm{H}, E-\mathrm{CH}=\mathrm{CH}-), 6.65(\mathrm{~d}$, $J=9.0 \mathrm{~Hz}, 2 \mathrm{H}), 6.64(\mathrm{~d}, J=9.0 \mathrm{~Hz}, 2 \mathrm{H}), 4.02(\mathrm{t}, J=6.5 \mathrm{~Hz}$, $\left.2 \mathrm{H},-\mathrm{OCH}_{2}-\right), 3.89\left(\mathrm{~s}, 3 \mathrm{H},-\mathrm{OCH}_{3}\right), 3.37\left(\mathrm{~m}, 8 \mathrm{H},-\mathrm{NCH}_{2}-\right)$, $2.49\left(\mathrm{q}, J=7.5 \mathrm{~Hz}, 2 \mathrm{H},-\mathrm{CH}_{2} \mathrm{SH}\right), 1.84(\mathrm{~m}, 2 \mathrm{H}), 1.58(\mathrm{~m}$, $2 \mathrm{H}), 1.54(\mathrm{~m}, 2 \mathrm{H}), 1.32(\mathrm{~m}, 12 \mathrm{H}), 1.17\left(\mathrm{~m}, 12 \mathrm{H},-\mathrm{NCH}_{2} \mathrm{CH}_{3}\right)$; ${ }^{13} \mathrm{C}$ NMR $\left(125 \mathrm{MHz}, \mathrm{CDCl}_{3}\right) \delta: 151.41,150.96,147.41$, $147.38,128.75,128.60,128.06,128.00,127.11,126.77,125.72$, $125.65,118.80,118.48,111.89,110.53,108.78,69.93,56.68$, $44.61\left(-\mathrm{NCH}_{2}-\right)$, 34.30, 29.93., 29.84, 29.77, 29.67, 29.31, 28.62, 28.07, 26.50, 24.90, $12.90\left(-\mathrm{NCH}_{2} \mathrm{CH}_{3}\right)$. El. Anal. Calcd. for $\mathrm{C}_{42} \mathrm{H}_{50} \mathrm{~N}_{2} \mathrm{O}_{2} \mathrm{~S}$ : C: 76.78, H: 9.20, N: 4.26, S: 4.88 Found C: $76.61, \mathrm{H}: 9.59, \mathrm{~N}: 4.41, \mathrm{~S}: 5.01$.

Synthesis of Solubilized, Chromophore Bound Silver Nanoparticles. Place exchange reaction $\mathrm{s}^{39}$ on nanoparticles were performed by dissolving the thiol-functionalized chromophore in a solution of silver nanoparticles (mean diameter $=10 \mathrm{~nm}$ ) coated with a 3:1 mixture of dodecyl- and octyl-thiol (synthesized using a modification of a literature method ${ }^{40}$ ) in $\mathrm{CH}_{2} \mathrm{Cl}_{2}$ and stirring for 4 days at room temperature.

Octylthiol/dodecylthiol Protected Silver Nanoparticles: $\mathrm{AgNO}_{3}(3.06 \mathrm{~g}, 18 \mathrm{mmol})$ and ethanol $(2700 \mathrm{~mL})$ were placed in a $4 \mathrm{~L}$ threeneck round-bottom flask with a mechanical stirrer. After complete dissolution of the silver salt, octylthiol $(670 \mu \mathrm{L}$, $4 \mathrm{mmol})$ and dodecyl dodecylthiol $(479 \mu \mathrm{L}, 2 \mathrm{mmol})$ were injected simultaneously with vigorous stirring resulting in a milky white dispersion. The solution was stirred for $5 \mathrm{~min}$. Then $\mathrm{NaBH}_{4}(1000 \mathrm{~mL}$ saturated solution in EtOH) was added very slowly. After addition of a few drops of $\mathrm{NaBH}_{4}$, the solution became purple and then the rate of addition was slightly increased. Upon complete addition, after ca. $4 \mathrm{~h}$, the reaction mixture was stirred for another $1.5 \mathrm{~h}$ and then kept in a refrigerator overnight, in order to allow the nanoparticles to precipitate from solution. The solution was filtered carefully over quantitative filter paper, and the filtrate was washed with water and acetone, and dried under vacuum. Yield: $1.98 \mathrm{~g}$ (68\%).

Bis(diethylamino)bis(styryl)benzene Functionalized Nanoparticles: Octylthiol/dodecylthiol protected silver nanoparticles $(150 \mathrm{mg})$ and 11-(2,5-bis $\{(E)-2$-[4-(diethylamino)phenyl]ethenyl\}-4-methoxyphenoxy)undecan-1-thiol, B, $(50 \mathrm{mg}, 0.076$ mmol), were dissolved in $\mathrm{CH}_{2} \mathrm{Cl}_{2}(300 \mathrm{~mL})$ and stirred for 4 days. After evaporation of the solvent the nanoparticles were suspended in acetone, filtered, and washed extensively with acetone until excess dye was removed completely, as checked by monitoring the fluorescence of the extract. Isolated yield: $80.5 \mathrm{mg}$. The nanoparticles were characterized by UV - vis and fluorescence spectroscopy, elemental analysis (found (\%) C: $19.43 \mathrm{H}: 2.81 \mathrm{~N}: 0.62 \mathrm{~S}: 3.15 \mathrm{Ag}: 71.08)$. The molar ratio dye:octylthiol:dodecylthiol was determined to be 1.2:4.2:1 from the elemental analysis.

Two-Photon-Excited Fluorescence Measurements. TPF measurements were conducted using a cw mode-locked Ti: sapphire laser (Spectra-Physics Millennia/Tsunami combination) giving $\sim 100 \mathrm{fs}$ pulses at a repetition rate of $82 \mathrm{MHz}$, a wavelength tunable over the range from $\sim 700$ to $1050 \mathrm{~nm}$, and an average power up to $\sim 500 \mathrm{~mW}$, and using an optical parametric oscillator (OPO) system (Spectra Physics Pro250/ MOPO combination) giving $\sim 6 \mathrm{~ns}$ pulses at a repetition rate of $10 \mathrm{~Hz}$.

For the measurements of the two-photon excitation spectrum of the polymer in solution, the laser beam was expanded to a diameter of $\sim 1 \mathrm{~cm}$ and then focused using a $76 \mathrm{~mm}$ focal length lens into a $1 \mathrm{~cm}$ path length cell. The TPF was collected in a right angle geometry and separated from any scattered laser light using a combination of short wavelength passing filters and a monochromator. The TPF was detected at $570 \mathrm{~nm}$ for both the sample and a reference solution with known $\eta \delta$ (Coumarin 307 in methanol ${ }^{41}$ ), to obtain $\eta \delta$ of the sample, after correction for the different emission spectra of the sample and reference standard, which are taken to be the same as the one-photon excited emission spectra. TPF excitation measurements with the nanosecond OPO system were performed according to methods described previously. ${ }^{24}$

One- and two-photon-excited fluorescence measurements on the dye-coated particles and free dye in toluene were performed at similar dye concentrations and were normalized for differences in concentration. The weight percentage of the dye in the dye coated nanoparticles was determined from the elemental analysis. The absorption spectrum of the dye coated nanoparticles closely matched the sum of the spectra of the nanoparticles without dye and that of the free dye (all in toluene), suggesting that the dye bound to the nanoparticles has essentially the same extinction coefficient as the free dye.

TPF measurements on films were performed using the collimated $\sim 3 \mathrm{~mm}$ diameter beam, at incident angles between $0^{\circ}$ and $45^{\circ}$, and collecting the emission at an angle between $60^{\circ}$ and $90^{\circ}$ to the incident beam (chosen to avoid specular reflection of the incident beam through the collecting lens). The emission was analyzed using a spectrograph with liquid nitrogen cooled CCD detection. For the measurements on the chromophoric polymer coated silver cluster films, the enhancement factors were determined relative to the TPF signal from neat polymer films of the same thickness. The mass of polymer per surface area in these films was determined gravimetrically from the known concentration and amount $(1-2 \mathrm{~mL})$ of the solutions cast on the given surface area of the substrate (e.g., $19 \mathrm{~cm}^{2}$ ). Nominal polymer thicknesses were subsequently obtained by assuming a density of $1200 \mathrm{~kg} / \mathrm{m}^{3}$, as for similar polymers. Thus, being a ratio of TPF signals for the same amount of polymer, the enhancement factor determined for these samples reflects the enhancement of the two-photon-excited fluorescence, in other words the effective enhancement of the product $\eta \delta$.

For all the other measurements on films, enhancement factors were still determined by comparison of the TPF signals of films under study with TPF signals of control samples (dye-doped PMMA films) without silver and containing approximately the same amount of dye, with normalization performed using the one-photon excited fluorescence signals as a relative measure of concentration. In this alternative referencing scheme, the enhancement factor is thus calculated as

$$
\frac{\left(S_{\mathrm{comp}}^{(2)}-S_{\mathrm{control}}^{(2)}\right) / S_{\mathrm{comp}}^{(1)}}{S_{\mathrm{dye}}^{(2)} / S_{\mathrm{dye}}^{(1)}}
$$

where $S_{\text {comp }}, S_{\text {control }}$, and $S_{\text {dye }}$ are the signals for the composite, the background signal (if any) from the control film without dye, and the signal from the reference dye doped PMMA film, 
respectively. The superscripts 1 and 2 refer to fluorescence signals obtained under one- and two-photon excitation, respectively. No significant emission from the control samples was detected under one-photon excitation, nor was there any significant background for PMMA films without dye. This alternative referencing scheme may be justified by the fact that the theoretical models of the plasmon localization in fractal clusters predict no net enhancement (spatially averaged) for linear optical effects because the fraction of nanoparticles involved in the localized plasmon modes is inversely proportional to the peak enhancement factor. ${ }^{42}$ However, a small enhancement of the one-photon excited fluorescence cannot be excluded. Because of the normalization using the one-photon excited fluorescence signals in this alternative referencing scheme, any changes in the fluorescence quantum yield are also eliminated. In other words, these measurements are effectively normalized for the concentration as well as the fluorescence quantum yield $\eta$, and for any enhancement of the linear absorption. The enhancement factors obtained for these film samples reflect an effective enhancement of the ratio $\delta / \sigma$, where $\sigma$ is the linear absorption cross-section. Thus, neglecting enhancement of the linear absorption, the enhancement factors reported for these samples can be interpreted as an effective two-photon absorption enhancement (effective $\delta$; as opposed to the effective TPF enhancement, or effective $\eta \delta$, reported for the polymer coated fractal cluster films). As a smaller enhancement of the linear absorption cannot be excluded, these TPA enhancement factors represent lower limits.

Acknowledgment. Support of this work by the NSF Biophotonics Program (Grant No. BES0086944), the Office of Naval Research (through the CAMP MURI program, Grant No. N0001401106), and the National Institutes of Health (Grant No. 5R01RR14312-02) is gratefully acknowledged. TMF acknowledges support from the DFG. The authors thank Mr. Phil Anderson for technical assistance with the TEM imaging.

Supporting Information Available: Optical absorption spectra of silver colloids and sedimented films. Transmission electron microscopy images of nanoparticle films. This material is available free of charge via the Internet at http://pubs.acs.org.

\section{References and Notes}

(1) Gehr, R. J.; Boyd, R. W. Chem. Mater. 1996, 8, 1807-1819.

(2) Kneipp, K.; Kneipp, H.; Itzkan, I.; Dasari, R. R.; Feld, M. S. Chem. Rev. 1999, 99, 2957-2975.

(3) Boyd, G. T.; Rasing, T.; Leite, J. R. R.; Shen, Y. R. Phys. Rev. B 1984, 30, 519-526.

(4) Shalaev, V. M. Phys. Rep. 1996, 272, 61-137.

(5) Denk, W.; Strickler, J. H.; Webb, W. W. Science 1990, 248, 7376.

(6) Parthenopoulos, D. A.; Rentzepis, P. M. Science 1989, 245, 843845 .

(7) Cumpston, B. H.; Ananthavel, S. P.; Barlow, S.; Dyer, D. L.; Ehrlich, J. E.; Erskine, L. L.; Heikal, A. A.; Kuebler, S. M.; Lee, I.-Y. S.; McCord-Maughon, D.; Qin, J.; Röckel, H.; Rumi, M.; Wu, X.-L.; Marder, S. R.; Perry, J. W. Nature 1999, 398, 51-54.

(8) Bhawalkar, J. D.; He, G. S.; Prasad, P. N. Rep. Prog. Phys. 1996, $59,1041-1070$.

(9) Kano, H.; Kawata, S. Opt. Lett. 1996, 21, 1848-1850. As the enhancement on these smooth films is spatially homogeneous, there is no distinction between a "peak" or "spatially averaged" enhancement factor. However, the enhancement only occurs at a very specific incident angle, and the factor of 90 mentioned represents the peak enhancement occurring for an incident angle of $56.4^{\circ}$.

(10) Glass, A. M.; Wokaun, A.; Heritage, J. P.; Bergman, J. G.; Liao, P. F.; Olson, D. H. Phys. Rev. B 1981, 24, 4906-4909. The factor of 150 mentioned is the area-averaged enhancement factor.

(11) Sanchez, E. J.; Novotny, L.; Xie, X. S. Phys. Rev. Lett. 1999, 82 , 4014-4017.
(12) Goncher, G. M.; Parsons, C. A.; Harris, C. B. J. Phys. Chem. 1984, $88,4200-4209$

(13) Shalaev, V. M.; Stockman, M. I. Zh. Eksp. Teor. Fiz. 1987, 92, 509-522 [Sov. Phys. JETP 1987, 65, 287-294].

(14) Shalaev, V. M.; Botet, R.; Butenko, A. V. Phys. Rev. B 1993, 48, $6662-6664$

(15) Mandelbrot, B. M. The Fractal Geometry of Nature (Freeman, San Francisco, 1982).

(16) Tsai, D. P.; Kovacs, J.; Wang, Z. H.; Moskovits, M.; Shalaev, V. M.; Suh, J. S.; Botet, R. Phys. Rev. Lett. 1994, 72, 4149-4152.

(17) Pettinger, B.; Picardi, G.; Schuster, R.; Ertl, G. Electrochem. 2000, $68,942-949$.

(18) Butenko, A. V.; Shalaev, V. M.; Stockman, M. I. Z. Phys. D 1988, $10,81-92$.

(19) Kim, W.; Safonov, V. P.; Shalaev, V. M.; Armstrong, R. L. Phys. Rev. Lett. 1999, 82, 4811-4814.

(20) Reduction of lasing threshold has also been reported in titania fractal colloids [Wang, H. Z.; Zhao, F. L.; He, Y. J.; Zheng, X. G.; Huang, X. G.; Wu, M. M. Opt. Lett. 1998, 23, 777-779].

(21) Butenko, A. V.; Chubakov, P. A.; Danilova, Y. E.; Karpov, S. V.; Popov, A. K.; Rautian, S. G.; Safonov, V. P.; Slabko, V. V.; Shalaev, V. M.; Stockman, M. I. Z. Phys. D. 1990, 17, 283-289.

(22) Sánchez-López, J. C.; Fernández, A. Act. Mater. 2000, 48, 37613771.

(23) Albota, M.; Beljonne D.; Brédas, J.-L.; Ehrlich, J. E.; Fu, J. Y.; Heikal, A. A.; Hess, S. E.; Kogej, T.; Levin, M. D.; Marder, S. R.; McCordMaughon, D.; Perry, J. W.; Röckel, H.; Rumi, M.; Subramaniam, C.; Webb, W. W.; Wu, X. L.; Xu, C. Science 1998, 281, 1653-1656.

(24) Rumi, M.; Ehrlich, J. E.; Heikal, A. A.; Perry, J. W.; Barlow, S.; Hu, Z. Y.; McCord-Maughon, D.; Parker, T. C.; Röckel, H.; Thayumanavan, S.; Marder, S. R.; Beljonne, D.; Brédas, J.-L. J. Am. Chem. Soc. 2000 , $122,9500-9510$.

(25) Xu, C.; Webb, W. W. J. Opt. Soc. Am. B 1996, 13, 481-491.

(26) Berlman, I. B. Handbook of fluorescence spectra of aromatic molecules (Academic Press: New York, 1971)

(27) A background emission from the neat Ag cluster film was observed. This emission was much weaker and broader than the TPF from the $\mathrm{Ag} /$ polymer composites, and also showed a quadratic power dependence. A broadband background, but with a different spectral distribution and higher power dependence on incident intensity, has also been observed in studies of surface enhanced second-harmonic generation from roughened silver surfaces (Chen, C. K.; de Castro, A. R. B.; Shen, Y. R. Phys. Rev. Lett. 1981, 46, 145-148). "White-light" generation and second harmonic generation has also been previously observed for fractal aggregates of $\mathrm{Ag}$ particles (Ducourtieux, S.; Gresillon, S.; Boccara, A. C.; Rivoal, J. C.; Quelin, X.; Gadenne, P.; Drachev, V. P.; Bragg, W. D.; Safonov, V. P.; Podolosky, V. A.; Ying, Z. C.; Armstrong, R. L.; Shalaev, V. M. J. Nonlinear Opt. Phys. Mat. 2000, 9, 105-116). Other possibly related phenomena include the background often observed in SERS (Michaels, A. M.: Nirmal, M.; Brus, L. E. J. Am. Chem. Soc. 1999, 121, 9932-9939), the photoinduced fluorescence observed from metal nanoparticles (Peyser, L. A.; Vinson, A. E.; Bartko, A. P.; Dickson, R. M. Science 2001, 291, 103-106; Mohamed, M. B.; Volkov, V.; Link, S.; El-Sayed, M. A. Chem. Phys. Lett. 2000, 317, 517-523). Further study is needed to understand the origin of this background.

(28) Markel, V. A.; Shalaev, V. M.; Zhang, P.; Huynh, W.; Tay, L.; Haslett, T. L.; Moskovits, M. Phys. Rev. B 1999, 59, $10903-10909$

(29) Perhaps surprisingly, this resolution is comparable to the resolution obtained in some near field optical imaging studies of the local intensity distribution near metal fractal cluster surfaces [see e.g., refs 14, 28, and (Bozhevolnyi, S. I.; Markel, V. A.; Coello, V.; Kim, W.; Shalaev, V. M.; Phys. Rev. B. 1998, 58, $11441-11$ 448.)]. Although the resolution of nearfield optical techniques can in general be higher, it is limited when applied to rough surfaces because of the finite tip size and especially, when using the constant intensity mode of controlling the tip height, because of the large spatial intensity variations which cause the tip to move further from the sample when approaching a hotspot. In contrast, the resolution of twophoton microscopy, albeit generally lower than that of near-field techniques, is not dependent on surface topography and even allows imaging through an arbitrarily thick polymer film. Another advantage of two-photon microscopy over near-field techniques is that no tip is involved. Scanning a near-field tip, which is typically metal coated or made entirely out of metal, in close proximity to the metal fractal clusters would itself be expected to significantly change the coupled plasmon modes as the image is acquired.

(30) Sarychev, A. K.; Shubin, V. A.; Shalaev, V. M. Phys. Rev. B 1999, $60,16389-16408$.

(31) Sandhyarani, N.; Pradeep, T.; Chakrabarti, J.; Yousuf, M.; Sahu, H. K. Phys. Rev. B 2000, 62, R739-R742.

(32) Jullien, R.; Botet, R., Aggregation and Fractal Aggregates; World Scientific: Singapore, 1987.

(33) Shalaev, V. M.; Poliakov, E. Y.; Markel, V. A. Phys. Rev. B. 1996, $53,2437-2449$.

(34) Sennett, R. S.; Scott, G. D. J. Opt. Soc. Am. 1950, 40, 203-211. 
(35) See for example: Liebermann, T.; Knoll, W.; Sluka, P.; Hermann, R. Colloids \& Surfaces A, 2000, 169, 337-350.

(36) Lee, P. C.; Meisel, D. J. Phys. Chem. 1982, 86, 3391-3395.

(37) Mangel, T.; Eberhardt, A.; Scherf, U.; Bunz, U. H. F.; Mulllen, K. Macromol. Rapid Comm. 1995, 16, 571.

(38) Xiao, Y.; Yu, W. L.; Chua, S. J.; Huang, W. Chem. Eur. J. 2000, $6,1318-1321$.
(39) Ingram, R. S.; Hostetler, M. J.; Murray, R. W. J. Am. Chem. Soc. 1997, 119, 9175-9178.

(40) Kang, S. Y.; Kim, K. Langmuir 1998, 14, 226-230.

(41) Xu, C.; Williams, R. M.; Zipfel, W.; Webb, W. W. Bioimaging 1996, 4, 198-207.

(42) Shalaev, V. M.; Botet, R.; Tsai, D. P.; Kovacs, J.; Moskovits, M. Phys. A 1994, 207, 197-207. 